\title{
Localization of Arginine Biosynthetic Enzymes in Renal Proximal Tubules and Abundance of mRNA during Development
}

\author{
SIDNEY M. MORRIS, JR., WILLIAM E. SWEENEY, JR., DIANE M. KEPKA, \\ WILLIAM E. O'BRIEN, AND ELLIS D. AVNER \\ Department of Molecular Genetics and Biochemistry, University of Pittsburgh School of Medicine, Pittsburgh, \\ Pennsylvania 15261, Howard Hughes Institute and Institute for Molecular Genetics, Baylor College of Medicine, \\ Houston, Texas 77030, and Division of Nephrology, Children's Hospital and Medical Center, \\ Seattle, Washington 98105.
}

\begin{abstract}
Argininosuccinate synthetase and argininosuccinate lyase catalyze the conversion of citrulline to arginine in kidney. Immunohistochemical staining of mouse kidney sections with antibodies to these two enzymes, compared with the staining patterns of known markers for proximal tubules, demonstrated that these enzymes are localized within the proximal tubules. The relative abundance of mRNA encoding argininosuccinate synthetase and argininosuccinate lyase during fetal and postnatal development of mouse kidney was also determined. Changes in relative abundance of these $\mathrm{mRNA}$ in kidney are coordinate during development, paralleling the developmental profile of phosphoenolpyruvate carboxykinase mRNA, which is also expressed in proximal tubules. Although relative abundances of the mRNA are comparable in liver and kidney of adult mice, the profiles of mRNA abundance during development of these two organs are distinct. The results indicate that these enzymes and their corresponding mRNA can serve as useful markers for examining the differentiation and development of renal proximal tubules in vivo and in cultured explants. (Pediatr Res 29: 151-154, 1991)
\end{abstract}

\section{Abbreviations}

AS, argininosuccinate synthetase AL, argininosuccinate lyase $\gamma$-GTP, $\gamma$-glutamyltranspeptidase TH, Tamm-Horsfall glycoprotein PEPCK, phosphoenolpyruvate carboxykinase

The kidney is a major site of arginine synthesis in vivo (1). Adequate supplies of arginine are essential for maintenance of normal growth rates after birth (2-4) and recovery from protein malnutrition (5), indicating the physiologic significance of this metabolic pathway. Conversion of citrulline to arginine in the kidney is catalyzed by AS [L-citrulline: L-aspartate lyase (AMPforming), $\mathrm{EC}$ 6.3.4.5] and $\mathrm{AL}$ (L-argininosuccinate arginine lyase, EC 4.3.2.1) (6). These enzymes were reported previously to be localized predominantly within the renal medulla (7). However, mRNA encoding these enzymes were found recently

Received March 14, 1990; accepted October 15, 1990.

Correspondence: Sidney M. Morris, Jr., Ph.D., Department of Molecular Genetics and Biochemistry, University of Pittsburgh School of Medicine, Pittsburgh, PA 15261

Supported in part by Grants DK 33144 (S.M.M.) and DK 34891 (E.D.A.) from the National Institutes of Health. to be localized exclusively in the renal cortex (8). Because knowledge of the localization of these enzymes within the kidney is essential for understanding their role in renal metabolism, immunohistochemical techniques were used to establish that AS and AL are expressed in the proximal tubules of the renal cortex.

Given that AS and AL are localized in the proximal tubules, it was of interest to determine the relative abundance of the corresponding mRNA as the metanephros develops into nephrons. Changes in mRNA abundance during this period might reflect the degree of tubular cell differentiation or might also indicate responses to changes in circulating hormones or nutritional factors. Because AS and AL have half-lives of several days $(9,10)$, changes in relative abundance of the corresponding mRNA, which apparently have half-lives of several hours (11, 12 ), are more timely indicators of changes in gene expression during kidney development. Developmental profiles of relative abundance for $\mathrm{AS}$ and $\mathrm{AL} \mathrm{mRNA}$ have recently been determined for liver (13), where these enzymes form part of the urea cycle. Our study demonstrates that AS and AL mRNA undergo coordinate increases in abundance during kidney development, but the developmental profiles for these mRNA differ for liver and kidney.

\section{MATERIALS AND METHODS}

Animals. Female Swiss-Webster albino mice, made pregnant by timed matings, were supplied by Hilltop Lab Animals, Inc. (Scottsdale, PA) and Tyler Laboratories (Bellevue, WA). Experimental protocols were approved by the Animal Care and Use Committees of the University of Pittsburgh and the University of Washington.

Isolation and analysis of $R N A$. Kidneys were rapidly dissected from fetuses and neonates of the indicated ages and immediately frozen on dry ice. Kidneys for each time-point were pooled before extraction of RNA. Total kidney RNA was isolated and analyzed by Northern blot as previously described $(11,12)$. Relative abundance of specific mRNA was determined by liquid scintillation spectrometry of hybridized RNA bands after Northern blot analysis $(11,12)$. Cloned rat cDNA probes used for hybridization corresponded to AS (8), AL (14), PEPCK (15), glyceraldehyde-3-phosphate dehydrogenase (16), and $\beta$-tubulin (17).

Histology and immunohistochemistry. Fresh murine tissue was obtained from young adults $(2 \mathrm{mo})$ and fetuses or neonates at gestational d 13,15,17, 19,21, and 23 . Tissue was fixed in $3.5 \%$ paraformaldehyde (pH 7.4) for $1 \mathrm{~h}$ at $4^{\circ} \mathrm{C}$. Tissue was then washed, dehydrated through graded acetone, and infiltrated and embedded with Immunobed plastic embedding medium (Polysciences, Warrington, PA). For light microscopy, 3- $\mu \mathrm{m}$ sections 
were cut on an ultramicrotome, mounted on glass slides, and stained with hematoxylin.

Immunohistologic techniques were used on serial sections of murine renal tissue to clearly localize the antigenic expression of $\mathrm{AS}$ and AL to specific nephron segments. Discrete tubular segments were identified by specific staining with segment-specific antibodies and lectins as previously described (18-20). Proximal tubules were identified by staining with affinity-purified antibody to the brush border enzyme $\gamma$-GTP and the lectin Lotus tetragonolobus. Thick ascending limb-early distal tubular segments were identified by staining with affinity-purified antibody to $\mathrm{TH}$ and collecting tubules were identified by staining with the lectin Dolichos biflorus. Rabbit antibodies to AS an AL were prepared as described previously $(21,22)$. Antibodies to $\gamma$-GTP and TH were kindly provided by Drs. N. P. Curthoys (Colorado State University) and John R. Hoyer (University of Pennsylvania School of Medicine), respectively, and prepared by their previously described methods $(23,24)$. Biotinylated lectins were obtained from Sigma Chemical Company (St. Louis, MO) and all other antisera were DAKO immunochemicals (Accurate Chemical and Scientific Corporation, Westbury, NY). A total of six to eight kidneys for each gestational stage were used in the current studies, with five to six sets of serial sections assessed per kidney.

The specific immunostaining procedure used was our previously described postembedding technique specifically developed for immunolocalization of antigens and lectins in plastic sections of fetal murine tissue $(19,20,25,26)$. Trypsinized Immunobed sections were incubated with primary antibody (anti- $\gamma$-GTP, anti-TH at 1:100; anti-AS and -AL at 1:50) or biotinylated lectins $(1: 400)$ for $48 \mathrm{~h}$ at $4^{\circ} \mathrm{C}$. For antibodies, this was followed by sequential incubations with bridging swine anti-rabbit $\operatorname{IgG}(1: 20)$ and rabbit peroxidase-antiperoxidase-complex (1:100). For lectins, avidin peroxidase-antiperoxidase complex (1:600) replaced the bridging antibody step. In addition to substitution of primary antibody with preimmune rabbit serum, controls included staining after absorption of primary antibodies with purified antigens and primary biotinylated lectins with avidin as well as deletion of specific reagents at each step of the procedure. In such controls, no significant background staining was observed. Slides were photographed using Nomarski differential interference contrast.

\section{RESULTS AND DISCUSSION}

Immunohistochemical staining of mouse kidney sections with $\gamma$-GTP antibody (17; Fig. 1c) and Lotus tetragonolobus lectin (Fig. 1a) confirmed that these reference markers are localized to the proximal tubules. By comparison, $\mathrm{AS}$ and $\mathrm{AL}$ are also localized in the proximal tubules (Fig. $1 b$ and $d$ ). These results agree with a recent analysis of arginine biosynthesis rates in microdissected nephron segments from rat kidney (27) as well as the finding that AS and AL mRNA were present in renal cortex but not in medulla or papilla (8). Although AS and AL are soluble cytosolic enzymes, the immunohistochemical staining appeared more intense near the luminal face of the tubules, suggesting that uptake of citrulline from the glomerular filtrate and its subsequent conversion to arginine may be closely associated spatially. AS or AL immunohistochemical staining did not correspond to Dolichos biflorus lectin-stained collecting tubules (Fig. 1e), Tamm-Horsfall protein stained tubules (not shown), or glomeruli. The presence of AS and AL in the proximal tubules-rather than in the renal medulla, as originally reported (7) - is reasonable in that resorption of citrulline from the glomerular filtrate and its conversion to arginine for release into the blood are colocalized.

At $13 \mathrm{~d}$ of gestation, no immunoreactivity for AS or AL could be demonstrated in developing tubular elements distributed throughout the metanephric mesenchyme. This was in contrast to immunostaining for $\gamma$-GTP, which, as previously reported, was localized to the apical surface of developing renal vesicles (23). Immunoreactivity for $\mathrm{AS}$ and $\mathrm{AL}$ in proximal tubular
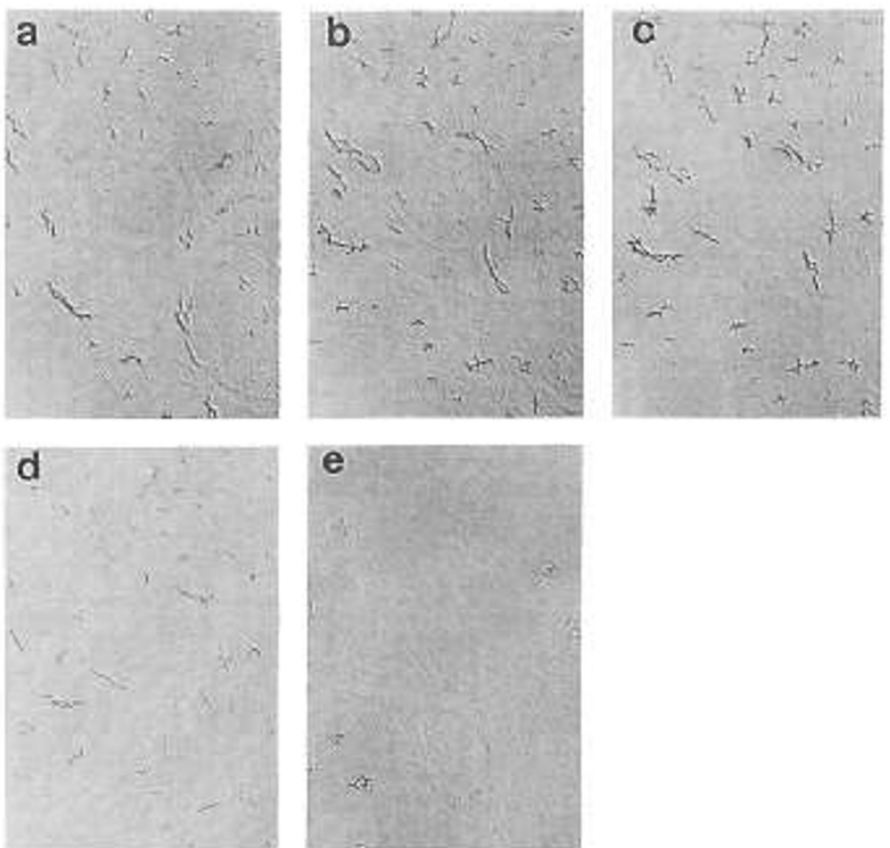

Fig. 1. Localization of AS and AL in young adult mouse kidney. Serial sections were stained, in order, for Lotus tetragonolobus lectin $(a)$, $\operatorname{AL}(b), \gamma$-GTP $(c)$, AS $(d)$, and Dolichos biflorus lectin (e). Original magnification $\times 100$.
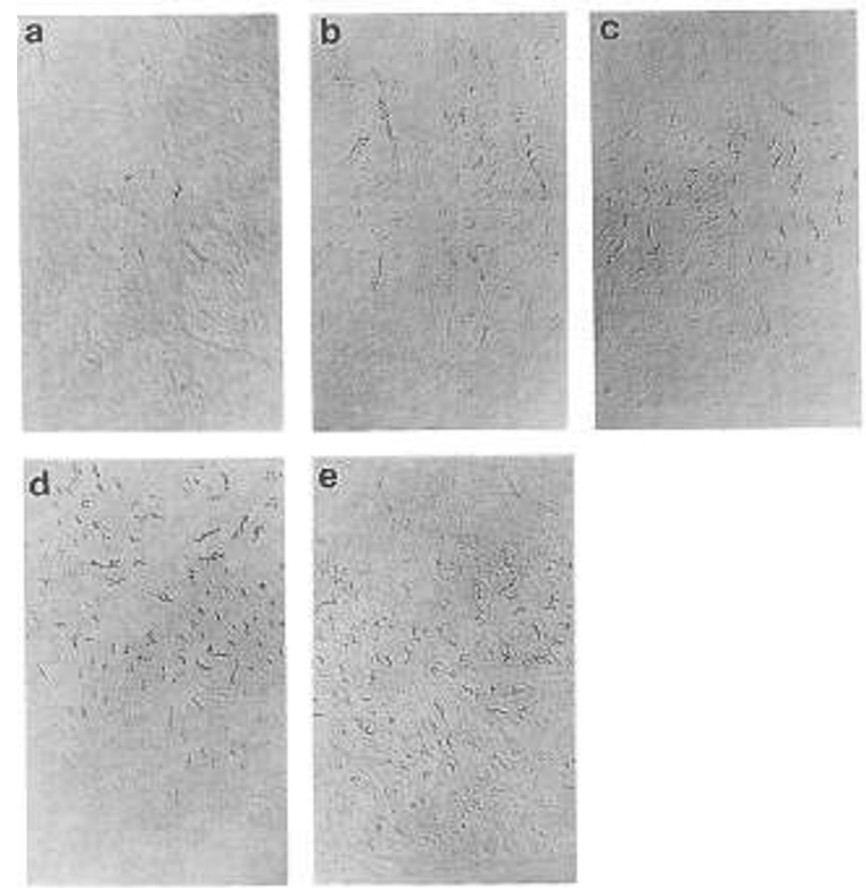

Fig. 2. Immunocytochemical localization of AL during fetal development. Kidney sections were fixed and stained as noted in Materials and Methods. At d $15(a)$, sparse immunoreactivity was present in a population of subcortical proximal tubules. At progressive stages of nephrogenesis-d $17(b), 19(c), 21(d)$, and $23(e)$-immunoreactivity increased and staining became localized to cortical regions of mature proximal tubules. This pattern of immunocytochemical staining was identical to that for AS. Original magnification $\times 100(a)$ or $\times 66(b-e)$.

epithelial cells appeared at $15 \mathrm{~d}$ of gestation and increased in intensity throughout fetal and postnatal nephrogenesis as exemplified in Figure 2. At no stage did other developing tubular segments, glomeruli, or Bowman's capsule react with anti-AL or anti-AS. This developmental pattern of immunolocalization to 
proximal tubules was identical to that of $\gamma$-GTP(19). Appearance of $\mathrm{AS}$ and $\mathrm{AL}$ immunoreactivity at $15 \mathrm{~d}$ gestation correlates morphologically with the development of the microvillar apparatus and apical-vacuolar network in proximal tubular epithelial cells (28).

To determine whether the developmental increase in immunoreactivity for AS and AL primarily reflected regulation at translational or posttranslational versus pretranslational steps in gene expression, relative abundances of the corresponding mRNA during renal development were determined. Messenger RNA for AS and AL were readily measurable at all stages of kidney development, with relative abundances of 2 and $7 \%$, respectively, as early as d 15 of gestation (Fig. 3). Expression of these two mRNA was strikingly coordinate throughout the fetal and neonatal periods. The developmental increases in AS and AL mRNA are specific, because relative mRNA abundance of the constitutively expressed glyceraldehyde-3-phosphate dehydrogenase is unchanged from $\mathrm{d} 15$ of gestation to adulthood (Fig. 3). This specificity in developmental expression is further dem-
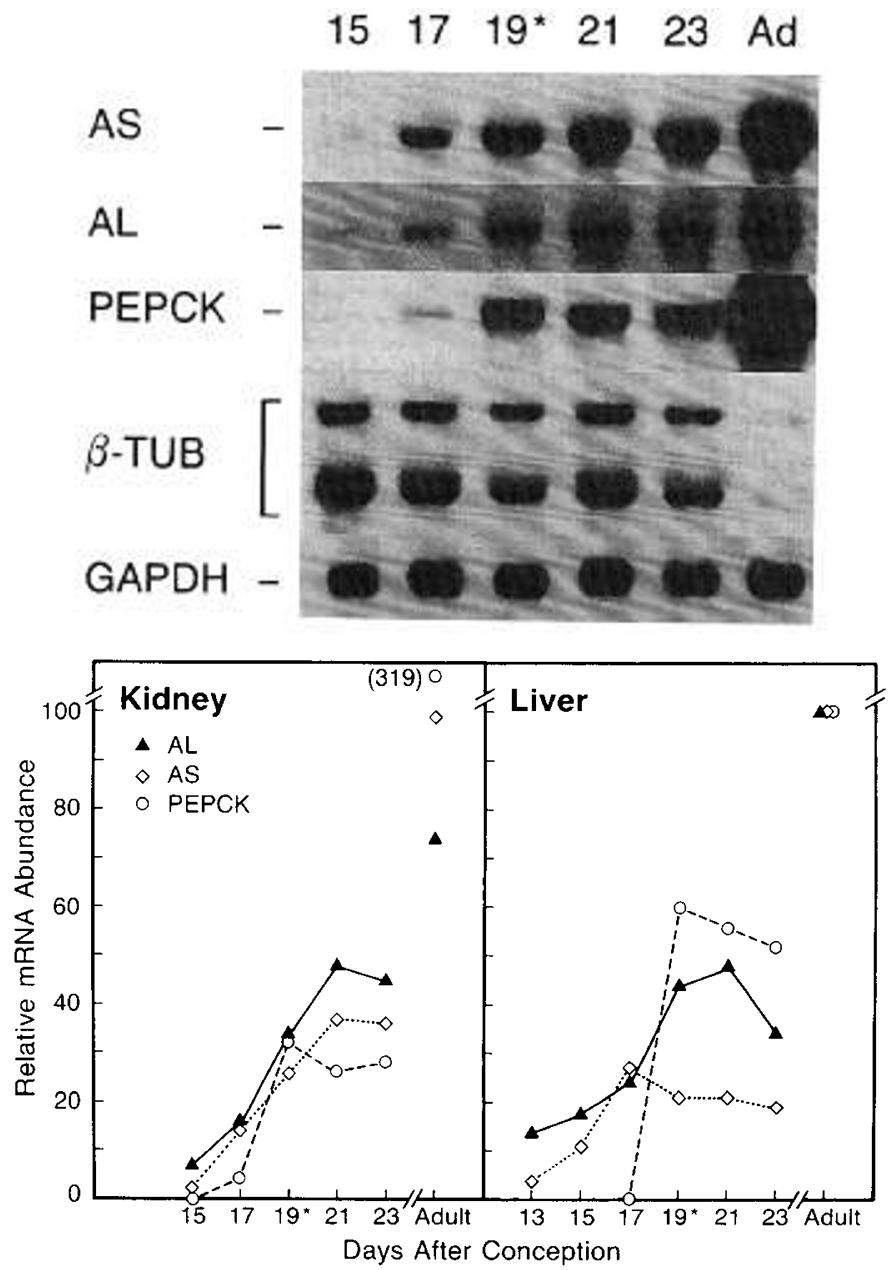

Fig. 3. Relative abundance of mRNA in fetal and neonatal mouse liver and kidney. Ten- $\mu \mathrm{g}$ aliquots of total RNA were subjected to Northern blot analysis as described in Materials and Methods. For d 15-19, RNA was extracted from livers and kidneys pooled from 15 mice; d 21 and 23, from nine mice; and adult, from three female mice. Upper panel: autoradiogram of Northern blots. Messenger RNA for $\beta$-tubulin $(\beta$ $T U B)$ and glyceraldehyde-3-phosphate dehydrogenase $(G A P D H)$ served as internal controls. Days after conception are indicated at the top of the panel; $A d=$ adult. Lower panel: Abundances of mRNA encoding AS, $\mathrm{AL}$, and PEPCK are expressed relative to the value determined for adult mouse liver. The asterisk denotes the day of birth. Values for liver mRNA are reproduced from reference 13 with permission of Academic Press. onstrated by the relative abundance of the $\beta$-tubulin mRNA, which also undergoes little change throughout fetal and neonatal periods but declines sharply in adults, presumably reflecting the much lower level of cell proliferation. The increases in AS and AL mRNA abundance during gestation and neonatal life are consistent with the increased immunoreactivity of these enzymes during this period, although the qualitative nature of the immunostaining precludes precise comparisons between relative mRNA and protein abundances. The increases in mRNA abundance likely reflect increased transcription of these genes, although regulation at posttranscriptional steps cannot be ruled out. The developmental increase in mRNA abundance probably reflects both an increased concentration of these mRNA per cell and an increase in the number of expressing cells. Notably, parturition had no impact on the steady linear increase in abundance of these mRNA during this period. In contrast, mRNA for PEPCK, which is also expressed in proximal tubules (29), sharply increased in relative abundance at birth in both kidney and liver (Fig. 3). Thus, developmental regulation of gene expression for AS and AL in kidney is similar but not identical to that of PEPCK, probably reflecting differences in responses to hormonal changes occurring at birth. This conclusion is in agreement with results of studies on hormonal regulation of AS and AL mRNA abundance in rat kidney (8) and effects of chromosomal deletions on abundance of AS, AL, and PEPCK mRNA in mouse kidney (30).

Because AS and AL are also expressed in liver as components of the urea cycle, it was of interest to compare the tissue-specific patterns of expression in the same animals. The development profiles for AL mRNA in liver and kidney are similar but not identical (Fig. 3). In contrast, the profiles for AS mRNA in liver and kidney are strikingly different. These comparisons suggest that there are cell-specific differences in intrinsic developmental programs or in responses to hormones or other factors. Organspecific differences in $\mathrm{AS}$ and $\mathrm{AL}$ gene expression have been observed previously with regard to effects of certain chromosomal deletions on AS and AL mRNA levels in mouse liver and kidney (30). These differences raise the possibility that kidneyspecific defects in AS or AL expression may exist. Unlike deficiencies in hepatic AS or AL, which result in hyperammonemia and death if untreated, renal AS or AL deficiency might result in modest growth retardation in infants, possibly accompanied by mild citrullinemia. Therefore, these defects would probably escape detection unless the diet were seriously deficient in arginine.

The small intestine of mice also contains significant amounts of $\mathrm{AS}$ and $\mathrm{AL}$ in the perinatal period. In contrast to liver and kidney, levels of AS and AL in small intestine of mice are high at birth and decline to barely measurable values in intestine of adult mice (31). This has been interpreted to suggest that the small intestine has significant capacity for endogenous arginine biosynthesis in the perinatal period, whereas the kidney has the predominant role for arginine biosynthesis in the adult $(31,32)$. Overall, the results indicate a complex pattern of developmental expression for the arginine biosynthetic enzymes in different organs.

Determination of the site and development of AS and AL expression in kidney are important for a better understanding of the role of arginine biosynthesis in renal physiology and in interorgan relationships during development and in disease. These enzymes and their corresponding mRNA should also serve as useful markers for further analysis of the differentiation and development of renal proximal tubules in vivo and in cultured explants.

\section{REFERENCES}

1. Featherston WR, Rogers R, Freedland RA 1973 Relative importance of kidney and liver in synthesis of arginine by the rat. Am J Physiol 224:127-129

2. Borman A. Wood TR, Black HC, Anderson EG, Oesterling MJ, Womack M, Rose WC 1946 The role of arginine in growth with some observations on the effects of argininic acid. J Biol Chem 166:585-594 
3. Rogers QR, Chen DM, Harper AE 1970 The importance of dispensable amino acids for maximal growth in the rat. Proc Soc Exp Biol Med 134:517-522

4. Hoogenraad N, Totino N, Elmer H, Wraight C, Alewood C, Johns RB 1985 Inhibition of intestinal citrulline synthesis causes severe growth retardation in rats. Am J Physiol 24:G792-G799

5. Kari FW, Ulman EA, Mulloy AL, Visek WJ 1981 Arginine requirement of mature protein-malnourished rats for maximal rate of repletion. J Nutr 111:1489-1493

6. Ratner S, Petrack B 1953 The mechanism of arginine synthesis from citrulline in kidney. J Biol Chem 200:175-185

7. Szepesi B, Avery EH, Freedland RA 1970 Role of kidney in gluconeogenesis and amino acid catabolism. Am J Physiol 219:1627-1631

8. Morris Jr SM, Moncman CL, Holub JS, Hod Y 1989 Nutritional and hormonal regulation of $\mathrm{mRNA}$ abundance for arginine biosynthetic enzymes in kidney. Arch Biochem Biophys 273:230-237

9. Schimke RT 1964 Enzymes of arginine metabolism in mammalian cell culture. $\mathrm{I}$. Repression of argininosuccinate synthetase and argininosuccinase. J Biol Chem 239:136-145

10. Tsuda M, Shikata Y, Kasunuma T 1979 Effect of dietary proteins on the turnover of rat liver argininosuccinate synthetase. J Biochem (Tokyo) 85:699-704

11. Morris Jr SM, Moncman CL, Rand KD, Dizikes GJ, Cederbaum SD, O'Brien WE 1987 Regulation of mRNA levels for five urea cycle enzymes in rat liver by diet, cyclic AMP, and glucocorticoids. Arch Biochem Biophys 256:343353

12. Nebes VL, Morris Jr SM 1988 Regulation of messenger ribonucleic acid levels for five urea cycle enzymes in cultured rat hepatocytes. Requirements for cyclic adenosine monophosphate, glucocorticoids, and ongoing protein synthesis. Mol Endocrinol 2:444-451

13. Morris Jr SM, Kepka DM, Sweeney Jr WE, Avner ED 1989 Abundance of mRNAs encoding urea cycle enzymes in fetal and neonatal mouse liver. Arch Biochem Biophys 269:175-180

14. Lambert MA, Simard LR, Ray PN, McInnes RR 1986 Molecular cloning of cDNA for rat argininosuccinate lyase and its expression in rat hepatoma cell lines. Mol Cell Biol 6:1722-1728

15. Yoo-Warren H, Monahan JE, Short J, Short H, Bruzel A, Wynshaw-Boris A, Meisner HM, Samols D, Hanson RW 1983 Isolation and characterization of the gene coding for cytosolic phosphoenolpyruvate carboxykinase (GTP) from the rat. Proc Natl Acad Sci USA 80:3656-3660

16. Fort P, Marty L, Piechaczyk M, el Sabrouty S, Dani C, Jeanteur P, Blanchard JM 1985 Various rat tissues express only one major mRNA species from the glyceraldehyde-3-phosphate-dehydrogenase multigenic family. Nucleic Acids Res 13:1431-1442

17. Bond JF, Robinson GS, Farmer SR 1984 Differential expression of two neural cell-specific $\beta$-tubulin mRNAs during rat brain development. Mol Cell Biol 4:1313-1319

18. Laitinen L, Virtanen I, Saxen L 1987 Changes in the glycosylation pattern during embryonic development of mouse kidney as revealed with lectin conjugates. J Histochem Cytochem 35:55-65

19. Curto KA, Sweeney WE, Avner ED, Piesco NP, Curthoys NP 1988 Immunocytochemical localization of gamma-glutamyltranspepetidase during fetal development of mouse kidney. J Histochem Cytochem 36:159-166

20. Avner ED, Sweeney WE 1990 Polypeptide growth factors in metanephric growth and segmental nephron differentiation. Pediatr Nephrol 4:372-377

21. O'Brien WE 1979 Isolation and characterization of argininosuccinate lyase from human liver. Biochemistry 18:5353-5356

22. O'Brien WE, Barr RH 1981 Argininosuccinate lyase: purification and characterization from human liver. Biochemistry 20:2056-2060

23. Tsao B, Curthoys NP 1980 The absolute asymmetry of orientation of glutamyltranspeptidase and aminopeptidase on the external surface of the rat renal brush border membrane. J Biol Chem 225:7708-7711

24. Hoyer JR, Resnick JS, Michael AF, Vernier RL 1978 Ontogeny of TammHorsfall urinary glycoprotein. Lab Invest 30:757-761

25. Avner ED, Sweeney WE, Ellis D 1989 In vitro modulation of tubular cyst regression in murine polycystic kidney disease. Kidney Int 36:960-968

26. Avner ED, Sweeney WE, Ellis D 1988 Congenital murine polycystic kidney disease II. Pathogenesis of tubular cyst formation. Pediatr Nephrol 2:210218

27. Hus-Citharel A, Morel F, Bankir L 1990 Production of arginine and urea from citrulline in proximal tubules of the rat kidney. Kidney Int 37:528(abstr)

28. Larsson L 1975 The ultrastructure of the developing proximal tubule in the rat kidney. J Ultrastruct Res 51:119-139

29. Burch HB, Narins RG, Chu C, Fagioli S, Choi S, McCarthy W, Lowry OW 1978 Distibution along the rat nephron of three enzymes of gluconeogenesis in acidosis and starvation. Am J Physiol 235:F246-F253

30. Morris Jr SM, Moncman CL, Kepka DM, Nebes VL, Diven WF, Dizikes GJ Cederbaum SD DeFranco D 1988 Effects of deletions in mouse chromosome 7 on expression of genes encoding the urea-cycle enzymes and phosphoenolpyruvate carboxykinase (GTP) in liver, kidney, and intestine. Biochem Genet 26:769-781

31. Hurwitz R Kretchmer N 1986 Development of arginine-synthesizing enzymes in mouse intestine. Am J Physiol 251:G103-G110

32. Riby JE, Hurwitz RE, Kretchmer N 1990 Development of arginine metabolism in the mouse intestine. Pediatr Res 28:261-265 